\title{
Research progress of biochar on agricultural soil improvement
}

\author{
Han Haojie ${ }^{1}$, Xia Qing ${ }^{1}$, Zhao Qin ${ }^{1}$, Zheng Caixia $^{1 *}$, and Zhang Zhiliang ${ }^{1}$ \\ ${ }^{1}$ Sichuan Agricultural University, College of Water Conservancy and Hydropower Engineering, 625014,Ya'an ,Sichuan, China
}

\begin{abstract}
Biochar is an environmentally friendly soil amendment produced by pyrolysis of biomass such as agricultural and forestry wastes or animal manure under anaerobic or highly anaerobic conditions. Due to its good physical structure and rich surface properties, it has gradually become a research hotspot in agricultural soil improvement. Based on the existing research results at home and abroad, this article systematically summarizes the properties of biochar, the production process and the mechanism of agricultural soil improvement so far. At the same time, the future scientific research on the effect of biochar in the field of agricultural soil improvement is put forward, aiming to provide a reference for it in the field of agricultural soil improvement.
\end{abstract}

\section{Introduction}

Biochar is an environmentally friendly soil amendment produced by pyrolysis of biomass such as agricultural and forestry wastes or animal manure under anaerobic or highly anaerobic conditions. It has a large specific surface area, rich surface functional groups, small specific gravity, rich pore structure and stable physical and chemical properties. The application of biochar to the soil can change the physical and chemical properties of the soil, thereby affecting the soil fertility and the process of field agricultural production.

He Xvsheng et al. ${ }^{[1]}$ believe that with the application of biochar in agriculture as the core, it can solve many problems in agriculture, energy, environment and climate, so as to achieve multiple effects. The starting components of biomass and the conditions for its conversion into carbon determine the differences in porosity, surface area, and surface chemical properties of biomass carbon materials ${ }^{[2]}$, as well as the differences in lignin and mineral content, and its thermal stability and carbon storage potential is also different ${ }^{[3]}$. In recent years, the production and agricultural applications of biochar have attracted great attention from many countries. Wei Chunhui et al. ${ }^{[4-5]}$ summarized the application of biochar in agriculture. Our country is a large agricultural country with a large population. The use of biochar for soil improvement and further improvement of soil fertility is of great significance for ensuring my country's food security.

\section{Preparation of biochar}

At present, there are two methods for the preparation of biomass charcoal: hydrothermal carbonization and dry pyrolysis carbonization. The hydrothermal carbonization method is to grind and pulverize biomass as raw materials under certain temperature and pressure, and seal it in a high-pressure reactor at $150 \sim 300^{\circ} \mathrm{C}$. The hydrolysis reaction occurs first, followed by the dehydration reaction and decarboxylation and aromatization process ${ }^{[6]}$. Dry pyrolysis carbonization method can be divided into slow pyrolysis method and fast pyrolysis method. Among them, slow pyrolysis is currently the main method for preparing biomass charcoal. Its heating rate is less than $1{ }^{\circ} \mathrm{C} \cdot \mathrm{s}^{-1}$, the reaction time is long, and the maximum temperature is $700^{\circ} \mathrm{C}$; while the heating rate of fast pyrolysis can reach $1000^{\circ} \mathrm{C}$ $\cdot \mathrm{s}^{-1}$, the highest temperature can reach $900^{\circ} \mathrm{C}$, but this method may damage the internal structure of biochar, resulting in a decline in production. In addition, the properties of biochar prepared by different carbonization processes will also show certain differences, which can be used to improve soils of different properties. For example, biochar prepared by dry pyrolysis carbonization method is usually alkaline and can be used for acid soil improvement ${ }^{[7]}$, while the biochar prepared by the hydrothermal carbonization method is usually acidic and can be used for the improvement of alkaline soil ${ }^{[8]}$. Current studies have shown that biochar has a very good effect on soil improvement in a short period of time, but in the long term, its effect on the soil needs to be further studied ${ }^{[9-13]}$.

\section{The physical and chemical properties of biochar}

The content of $\mathrm{C}$ element in biochar is usually greater than $60 \%$, and the other elements contained in it are mainly $\mathrm{H}, \mathrm{O}, \mathrm{N}, \mathrm{S}$, etc. ${ }^{[14]}$. The elemental composition and content of biochar are closely related to the reaction temperature in the production process, mainly in a certain range. With the increase of carbonization temperature,

*Corresponding author: caixia818@163.com 
the content of hydrogen and oxygen decreases, the content of carbon increases ${ }^{[15]}$. In addition, the solubility of biochar is extremely low, the boiling point is extremely high, and it has a high degree of carboxylic acid esterification, aromatization structure [16-17] and aliphatic chain structure ${ }^{[15]}$. It is precisely because of the typical structural features of biochar, such as aliphatic double bonds, carboxyl groups, phenolic hydroxyl groups, hydroxyl groups and aromatization ${ }^{[18]}$ that it has strong antioxidant capacity and adsorption capacity ${ }^{[15]}$. In the production process of biochar, the fine pore structure of the original material is well preserved, making the biochar become loose and porous, with a larger specific surface area. Abundant pore structure, high carbon content, stable physical and chemical properties and large specific surface area are the important material structure basis for biochar to improve soil characteristics, promote crop growth and increase yield.

\section{The mechanism of biochar on soil improvement}

The improvement effect of biochar on soil is mainly

Table 1. Effect of biochar application on soil propertie

\begin{tabular}{|c|c|c|c|c|}
\hline \multicolumn{2}{|c|}{ Soil factor classification } & Measures & Research result & References \\
\hline \multirow{4}{*}{\multicolumn{2}{|c|}{ Soil physical structure }} & \multirow{15}{*}{$\begin{array}{l}\text { Add } \\
\text { biochar }\end{array}$} & Soil bulk density decreased by $0.19 \mathrm{~g} / \mathrm{cm}^{3}$ & 22 \\
\hline & & & Improved soil permeability and water retention & 23 \\
\hline & & & Soil specific volume increases & $24,25,26,27$ \\
\hline & & & $\begin{array}{l}\text { Soil bulk density decreases, soil water holding } \\
\text { capacity and soil moisture content increase }\end{array}$ & 28 \\
\hline \multirow{9}{*}{$\begin{array}{c}\text { Soil } \\
\text { chemistry }\end{array}$} & Soil pH & & Increased soil pH & $32,33,34,35$ \\
\hline & \multirow{3}{*}{$\begin{array}{l}\text { Soil base } \\
\text { saturation } \\
\text { and cation } \\
\text { exchange } \\
\text { capacity }\end{array}$} & & $\begin{array}{l}\text { The total amount of exchangeable base ions in the } \\
\text { soil is significantly increased }\end{array}$ & 38 \\
\hline & & & Soil exchangeability $\mathrm{Na}^{+}$and $\mathrm{K}^{+}$increase & 40 \\
\hline & & & Increase the cation exchange capacity of the soil & 41 \\
\hline & \multirow{5}{*}{$\begin{array}{c}\text { Soil } \\
\text { nutrients }\end{array}$} & & Increase wheat's absorption of $\mathrm{N}$ and $\mathrm{P}$ & 42 \\
\hline & & & $\begin{array}{l}\text { The content of available phosphorus, available } \\
\text { nitrogen and available potassium has increased }\end{array}$ & 43,45 \\
\hline & & & $\begin{array}{l}\text { When the accumulated carbon application rate is too } \\
\text { high, the effective nitrogen and phosphorus content } \\
\text { will be too low }\end{array}$ & 44 \\
\hline & & & $\begin{array}{l}\text { Soil SOC/TN increases with the increase of biochar } \\
\text { dosage }\end{array}$ & 46 \\
\hline & & & $\begin{array}{l}\text { The total organic carbon content of the soil increases, } \\
\text { and the TN content increases }\end{array}$ & 47 \\
\hline \multirow{2}{*}{\multicolumn{2}{|c|}{ Soil microorganisms }} & & Soil microbial biomass increased & $52,53,54,36$ \\
\hline & & & Changes in microbial abundance & $56,57,58$ \\
\hline
\end{tabular}

with different proportions and different particle sizes of biochar, and found that when the content of biochar increases, the specific volume of the soil also increases. Li Yumei et al. ${ }^{[25]}$, Chen et al. ${ }^{[26]}$ and Laird et al. ${ }^{[27]}$ also reflected in the physical structure, chemical properties, soil microbial content, etc. The typical effects of biochar applied to the soil are summarized as shown in Table 1 .

\subsection{The impact of biochar on soil physical structure}

The deterioration of soil physical properties such as increased bulk density, decreased porosity, and decreased permeability can lead to poor coordination of soil water, fertilizer, gas and heat, thereby reducing soil fertility and reducing crop yields ${ }^{[19]}$. Biochar has a loose and porous structure similar to soil aggregates. After being applied to the soil, it can improve the soil's porosity, bulk density, aggregate distribution and other physical properties, thereby improving the air and moisture conditions in the soil ${ }^{[1,20-21]}$. Eastman ${ }^{[22]}$ after applying $25 \mathrm{~g} / \mathrm{kg}$ of biochar in silt soil, the soil bulk density decreased by $0.19 \mathrm{~g} / \mathrm{cm}^{3}$; after adding $5 \%$ of biochar, the water permeability and water retention of the soil are improved. Compared with perlite and vermiculite, its effect on soil compaction is more obvious ${ }^{[23]}$. Wenman et al. ${ }^{[24]}$ used the centrifuge method to measure the shrinkage characteristics of soil 
significant effect on soil color and soil thermal conditions. Briggs et al. ${ }^{[29]}$ found that after adding biochar to the soil, the Munsell color value increased with the increase of biochar content, while low water content the biochar will significantly increase the temperature of the soil ${ }^{[30]}$. From the perspective of improving the physical properties of the soil, proper application of biochar can produce good effects on agricultural soil.

\subsection{The impact of biochar on soil chemistry}

Biochar applied to farmland not only improves the physical properties of the soil, but also affects the chemical properties of the soil. The chemical properties of soil mainly include $\mathrm{pH}$, cation exchange capacity, base saturation and nutrients.

\subsubsection{Soil $\mathrm{pH}$}

The $\mathrm{pH}$ of biochar prepared by different treatment methods will show a certain difference in acidity and alkalinity, most of which are alkaline. When alkaline activated carbon is added to the soil, as the amount of application increases, the soil $\mathrm{pH}$ will increase, but its degree of influence is related to factors such as raw materials, soil types, and carbon production technology $[29,31]$. Liu et al. ${ }^{[32]}$ conducted field experiments in Zhejiang Province, China, and the results showed that bamboo biochar and straw biochar had little effect on soil $\mathrm{pH}$. Rice straw biochar could increase soil $\mathrm{pH}$ by 0.18 , and bamboo biochar could increase soil $\mathrm{pH}$ by 0.15 . Xv et al. ${ }^{[33]}$ found that rice straw charcoal, legume straw charcoal, corn straw charcoal, rape straw charcoal, and wheat straw charcoal can all increase soil $\mathrm{pH}$. Among them, legume straw charcoal has the most obvious effect on improving soil $\mathrm{pH}$. Li Ming et al. [34] indoor cultivation experiments showed that after 135 days of cultivation, the $\mathrm{pH}$ of the soil treated with two straw biochars increased by 0.16 on average compared with the control group; but at the same lysis temperature, the difference between the two biochar treatments was similar. Qiu Zhen ${ }^{[35]}$ found that Spartina alterniflora biochar applied to soil can significantly increase its $\mathrm{pH}$. As the growth period grows, the $\mathrm{pH}$ of the soil gradually tends to be neutral. This is due to the ion exchange of oxygen-containing functional groups on the surface of the biochar, the release of hydrogen ions and the respiration of soil organisms. Research by Shi Yvlong et al. ${ }^{[36]}$ showed that compared with the control group, the application of biochar in the coastal saline soil of the North China Plain can significantly reduce the soil $\mathrm{pH}$ in the $0-20 \mathrm{~cm}$ and $20-40 \mathrm{~cm}$ soil layers.

\subsubsection{Soil base saturation and soil cation exchange capacity.}

Soil base saturation refers to the percentage of exchangeable base ions on the soil colloid in the cation exchange capacity, reflecting the effective nutrient content of the soil, and is an important basis for improving soil. Soil cation exchange capacity (CEC) refers to the total amount of various cations adsorbed by soil colloids. It is an important basis for affecting the strength of soil buffering capacity, evaluating soil fertility retention capacity, reasonably applying fertilizers and improving soil.

The effective nutrients needed by plants are mainly provided by the base ions in the soil, including $\mathrm{K}^{+}, \mathrm{Ca}^{2+}$, $\mathrm{Mg}^{2+}, \mathrm{Na}^{+}$and $\mathrm{NH}^{4+}$. Because biochar has a loose and porous structure, its surface area is large and the surface is rich in organic functional groups, it can adsorb more base ions, thereby increasing the soil base saturation and making the CEC value higher ${ }^{[37]}$. Guo Chunlei et al. ${ }^{[38]}$ found that compared with single application of straw, under the condition of single application of biochar, the total amount of exchangeable base ions in the soil was significantly increased, while under the condition of equal amount of straw and equal nutrients, biochar The total exchangeable base was increased by $17.6 \%$ and $15.1 \%$, respectively, compared with chemical fertilizers and straw and chemical fertilizers compared with no fertilization. The difference between the two was significant, indicating that the use of straws as biochar in the field can improve soil exchangeable bases. The effect of total ion amount is obviously better than that of straw returning directly to the field. Applying biochar and straw to the soil can increase soil exchangeable $\mathrm{K}^{+}, \mathrm{Ca}^{2+}$ and $\mathrm{Mg}^{2+}$, of which $\mathrm{Ca}^{2+}$ is the main one. The exchange of $\mathrm{Ca}^{2+}$ with the hydrogen ion in the soil colloid will form calcium colloid, which is conducive to the formation of aggregate structure and enhances soil fertility attributes [39]. At the same time, Zhang Zhengrong ${ }^{[40]}$ showed that wheat straw biochar has a positive effect on the increase of soil exchangeability $\mathrm{Na}^{+}$ and $\mathrm{K}^{+}$. In addition, some studies have shown that adding biochar to alkaline lime soil can also significantly increase the cation exchange capacity of the soil [41].

\subsubsection{Soil nutrients.}

Soil nutrients are one of the basic properties of soil, and their content directly affects the growth quality and final yield of crops. Biochar has a loose and porous structure, abundant organic functional groups and a large specific surface area, so it can effectively absorb and maintain the nutrients needed by soil and plants. Kang Rifeng et al. ${ }^{[2]}$ added biochar combined fertilizers to the soil and found that biochar-based fertilizers can significantly increase the absorption of $\mathrm{N}$ and $\mathrm{P}$ by wheat, and within a certain range, with the increase of biochar, the absorption of $\mathrm{N}$ and $\mathrm{P}$ also increases. Liu Fang et al. ${ }^{[43]}$ added biochar to the soil, and the content of available phosphorus, available nitrogen and available potassium in the soil increased, which significantly improved the soil nutrient status. Wei Yongxia et al. ${ }^{[44]}$ showed that an appropriate amount of biochar can effectively improve soil fertility and promote crop growth, but when the cumulative amount of carbon application is too high, it will result in too low available nitrogen and phosphorus content, which is not conducive to crop growth. In addition, the application of biochar added with penicillium can improve its fertilizer efficiency ${ }^{[45]}$. In addition, studies 
have shown that increasing the application of biochar under the winter wheat-summer maize rotation system can significantly increase the soil organic carbon content, and under the same nitrogen level, the soil SOC/TN increases with the increase in the amount of biochar ${ }^{[46]}$. The study by Shang Jie et al. ${ }^{[47]}$ showed that in the $0-10 \mathrm{~cm}, 10-20 \mathrm{~cm}$ and $20-30 \mathrm{~cm}$ soil layers, the total organic carbon content of the soil applied with biochar increased by $65.14 \% \sim 180.80 \%$ and $54.70 \% \sim 180.68 \%$ respectively compared with the control group. And $35.90 \% \sim 37.41 \%$, the $\mathrm{TN}$ content increased by $11.59 \% \sim 33.33 \%, 3.03 \% \sim 25.76 \%$ and $15.69 \% \sim 31.37 \%$ respectively compared with the control group. Studies have also shown that the application of biochar significantly reduces soil $\mathrm{NO}^{2-}$ content, but has no significant effect on soil $\mathrm{NH}_{4}{ }^{+}$and $\mathrm{NO}^{3-}$ content ${ }^{[48]}$. With the increase of the amount of biochar applied, the soil available nitrogen gradually decreased, with a decrease of $10.0 \%$ to $20.3 \%$; the soil available potassium increased significantly ${ }^{[49]}$. Lv Zexian ${ }^{[50]}$ conducted a potato experiment and found that the application of biochar-based fertilizers has a greater increase in organic carbon, available potassium, available phosphorus and $\mathrm{C} / \mathrm{N}$ than the control soil. After biochar was applied to the soil for 5 years, the active organic carbon content in the soil was significantly reduced, but the stable organic carbon content changed little, and it had no significant effect on the dissolved organic carbon content and composition $^{[51]}$.

\subsection{The impact of biochar on soil microorganisms}

As an environmentally friendly soil amendment, biochar can change the physical structure of the soil after it is applied to the farmland, providing a good living environment for soil microorganisms. Kuang Chongting et al. ${ }^{[52]}$ found that as the amount of biochar applied increases, the microbial biomass will also increase. Applying $0.5 \%$ and $1 \%$ biochar to the soil greatly increased the soil microbial $\mathrm{MBC}$ and $\mathrm{MBN}$ content. Bargmann et al. ${ }^{[53]}$ found that biochar prepared from beer lees and beetroot was applied to the soil for a certain period of time, the soil microbial MBC was significantly higher than the control group. Tao Pengchuang et al. ${ }^{[54]}$ found that the combined application of unequal amounts of nitrogen fertilizer and biochar can significantly increase soil MBC and MBN. Song Dali et al. ${ }^{[46]}$ found that the amount of biochar and the level of nitrogen application have a certain effect on the soil MBC content, but it has little effect on MBN ${ }^{[55]}$. Studies have found that in the $0-20 \mathrm{~cm}$ soil layer of coastal saline soil in the North China Plain, after biochar and organic fertilizer treatment, soil microbial MBC and MBN are higher than the control [36]. In addition, studies have found that applying biochar in the soil can have a certain impact on the abundance of microorganisms, but the conclusions are not the same. For example, studies have shown that the application of biochar can increase the abundance of microorganisms ${ }^{[56]}$; short-term application of biochar in the soil cannot significantly change the microbial abundance ${ }^{[57]}$; after applying eucalyptus biochar, the soil microbial biomass is significantly reduced ${ }^{[58]}$. There are differences in the above studies, which are related to the type of biochar material, pyrolysis time and temperature, soil type, and the length of the test.

\section{Conclusion and prospects}

The use of biochar for soil improvement comes from the agricultural production experience of the ancestors in the Amazon basin, who discovered that biochar has an effect on crop yield. Once it appeared, it has aroused widespread concern in the agricultural field all over the world. In summary, the application of biochar for soil improvement has been extensively studied, and it has a significant effect on the rational use of biochar for agricultural development. Currently, the role of biochar as a soil amendment in agriculture is shown in Figure 1. 


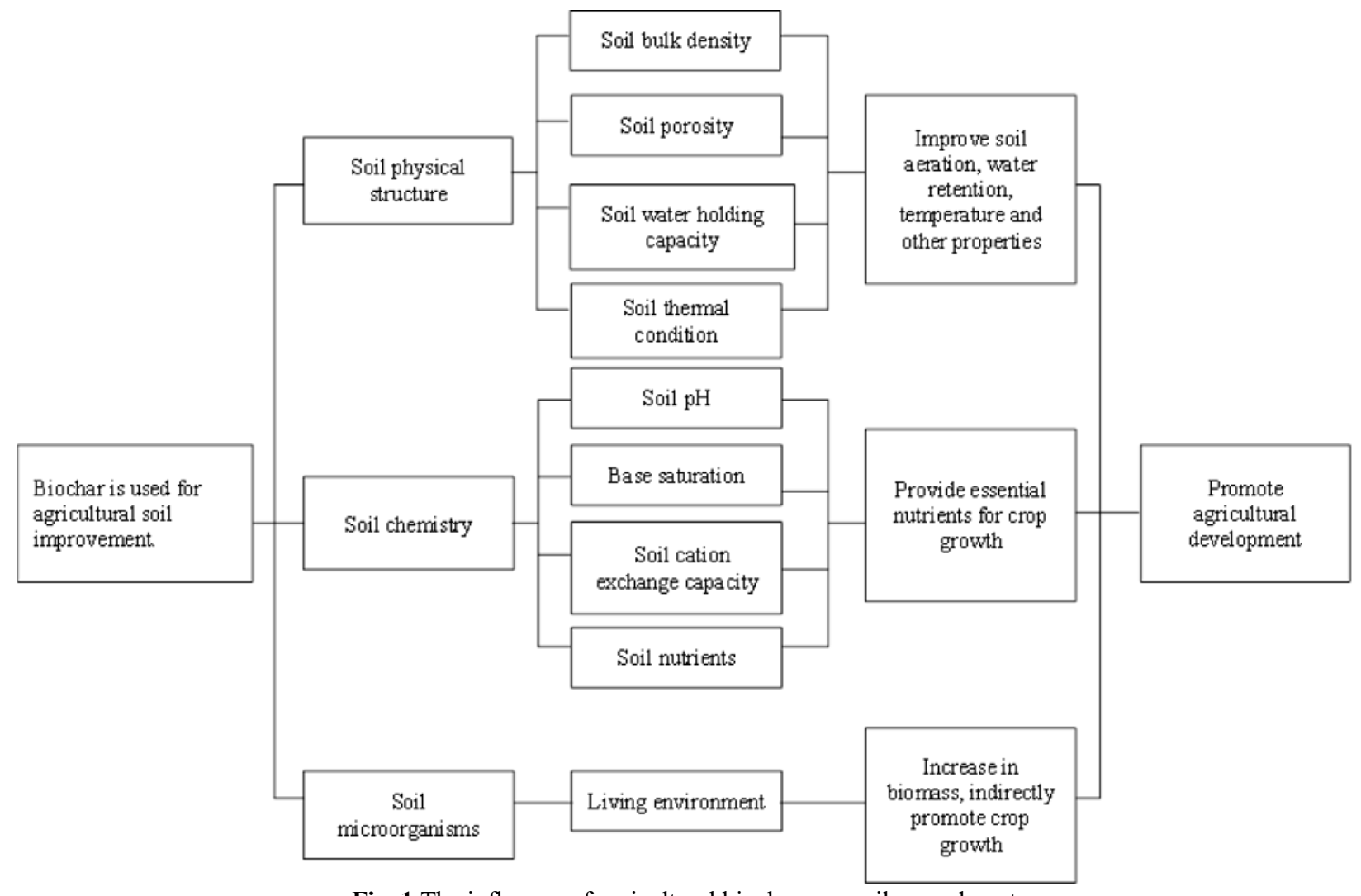

Fig. 1.The influence of agricultural biochar as a soil amendment

In view of the summary of the research on biochar, the following prospects are put forward for the future of agricultural biochar.

(1) At present, there are many research results on the improvement of soil characteristics by biochar, but most of the research is still in the small area test stage. How to select the type and amount of biochar and carry out large-scale soil improvement construction still needs in-depth analysis and research. In addition, for the large-scale application of biochar to improve crop soil in the future, it is necessary to comprehensively consider the benefits and economy to make biochar lower in cost and better in effect. Further research is still needed.

(2) Biochar is an excellent new environmentally friendly soil improvement material. The research and development of fertilizers that rely on biochar to play a higher role is of great significance to the promotion of agricultural revitalization and the sustainable development of ecological agriculture.

(3) The properties of biochar are subject to differences in raw materials, preparation methods and research methods; and the same biochar applied to different soils has different effects. Therefore, in the actual application process, it is necessary to actively carry out the standardization research and discussion of biochar. Formulate relevant industry standards and summarize the properties of biochar. According to different soil types and actual conditions, conduct research on the preparation and selection of suitable biochar to optimize the effect of biochar on soil improvement.

(4) The use of biochar to improve soil is a long process. Whether the soil improvement effect has long-term effects still needs more in-depth research.
(5) The research on the changes of soil characteristics caused by the co-application of biochar and other soil amendments or soil fertilizers is insufficient. Research can be carried out separately from the aspects of physical structure, chemical properties and microorganisms.

\section{Acknowledgments}

Authors thanks to the support of Sichuan Provincial Department of Science and Technology Project (2019YJ0430) and College Student Innovation Training Program (202010626139).

\section{References}

1. He X S, Geng Z C, She D, et al. (2011) Implications of production and agricultural utilization of biochar and its international dynamic. J. Transactions of the Chinese Society of Agricultural Engineering, 27(2):1-7.

2. Li Y F, Hu S D, Chen J H, et al. (2018) Effects of biochar application in forest ecosystems on soil properties and greenhouse gas emissions: a review. J. Journal of Soils and Sediments, 18(2):546-563.

3. Zhao J F, Chen J W, Zhang D, et al. (2019) Thermal stability and oxidation resistance of biochars derived from corn stalk and wheat stalk .J. Journal of Agro-Environment Science, 38(02):216-223.

4. Wei C H, Ren Y L, Liu F, et al. (2016) Research Progress of Application of Biochar and Biochar-based Fertilizer in Agriculture .J. Journal of Henan Agricultural Sciences, 45(003):14-19. 
5. Chen X X,Geng Z C. (2013) Application of biochar in agriculture .J. Journal of Northwest A \& F University(Natural Science Edition), 041(002):167-174.

6. Wang Z P, Chen L. (2019) Research progress on straw-based biochar .J. Applied Chemical Industry, 048(002):444-447.

7. Wang Y X, Xin S J, Ye J, et al. (2018) Improvement Effect of Biochar on Soil Acidity in Strong Acidity Tea Garden .J. Chinese Agricultural Science Bulletin, 34(12):108-111.

8. Wang Y X, Ye J, Weng B Q, et al. (2015) Method for improving saline-alkaline soil by using hydrothermal carbonization product of edible fungus residue: 201410463481. X[P].

9. Zhang J. (2017) The effect of Salix biochar on copper pollution repair function [D]. Huhehaote: Inner Mongolia Agricultural University.

10. Li P J, Liu W, Sun T H, etc. (2006) Remediation of contaminated soil: Its present research situation and prospect .J. Chinese Journal of Ecology, 25(12) : 1544-1548.

11. Hu L, Wei J J, Wang H C. (2019) Applications progess of biochar in agriculture production and environmental protection .J. Qinghai Prataculture, 28(3) : 26-30.

12. Lv B B, Zhang G Y, Zhang L P, et al. (2018) Application Progress of Biochar in Agriculture .J . Journal of Shanxi Agricultural Sciences, 46(12) : 2118-2121.

13. Wang F, Qu Z Y. (2018) Progress research on the improvement effect of biochar on salinized farmland soil .J. Journal of Northern Agriculture, 46(5):68-75.

14. Goldberg E D. (1985) Black carbon in the environment: properties and distribution. Environmental ence \& Technology.

15. Schmidt M W I, Noack A G. (2000) Black carbon in soils and sediments: Analysis distribution, implications, and current challenges. Global Biogeochemical Cyeles, 14(3): 777-794.

16. Joseph W J, Pignatello J J. ( 2003 ) Sorption hystersis of benzene in charcoal particles. Environmental Science and Technology,37(2): 409-417.

17. Kramer R W, Kujawinski E B, Hatcher P G. （2004） Identification of black carbon derived structures in a volcanic ash soil humicacid by Fourier transformion cyclotron resonance mass spectrometry. Environmental Science Technology,38(12): 3387-3395.

18. Titirici M M, Thomas A, Yu S, Yu S H, Müller J O, Antonietti M. ( 2007 ) A direct synthesis of mesoporous carbons with bicontinuous poremorphology from crude plant material by hydrothermal carbonization. Chemistry of Materials, 19: 4205-4212.

19. Nawaz M F , Guilhem Bourrié, Trolard F . (2013) Soil compaction impact and modelling. A review.J. Agronomy for Sustainable Development, 33(2):291-309.

20. Wang D, Zhang X, Jiang C C, et al. (2012) Biochar research advances regarding soil improvement and crop response .J. Chinese Journal of Eco-Agriculture , 20(8): 963-967.

21. Zhang X,Wang D, Jiang C C, et al. (2013) Effect of biochar on physicochemical properties of red and yellow brown soils in the South China Region .J. Chinese Journal of Eco-Agriculture ,21(8): 979-984.

22. Eastman C M. (2011) Soil Physical characteristics of an aeric ochraqualf amended with biochar[D]. Columbus: The Ohio State University.

23. Zhang W M. ( 2012 ) Physical and Chemical Properties of Biochar and Its Application in Crop Production [D]. Shenyang Agricultural University.

24. Wen M, Zheng J Y. (2012) Effects of Different Sizes of Biochar and Their Additiont Rates on Soil Shrinkage Characteristics .J. Research of Soil and Water Conservation, 19(1): 46-55.

25. Li Y M, Wang G L, Li X J, et al. (2014) Effects of bio-char on soil physical properties and clomazone degradation .J. Chinese Journal of Ecology, 33( 3) : $729-734$.

26. Chen Y, Shinogi Y, Taira M. (2010) Influence of biochar use on sugarcane growth, soil parameters, and groundwater quality.J. Australian journal of soil research, 48: 526-530.

27. Laird D A, Fleming P, Davis D D, et al. (2010) Impact of biochar amend- ments on the quality of a typical Midwestern agricultural soil.J. Geoder- ma, $158(3 / 4): 443-449$.

28. Liu Y, JAMAL KHAN M, Le H Y,et al. (2015) Effects of successive application of crop-straw biochar on crop yield and soil properties in cambosols.J. Acta Pedologica Sinica, 52(4):849 858 .

29. Briggs C M, Breiner J, Graham R, et al. (2005) Contributions of pinus ponderosa charcoal to soil chemical and physical properties. In The ASACSSA-SSSA International Annual Meetings Salt Lake City, USA.

30. $\mathrm{Wu} \mathrm{Y,} \mathrm{Xu} \mathrm{G,} \mathrm{Lv} \mathrm{Y} \mathrm{C,} \mathrm{et} \mathrm{al.} \mathrm{(2014)} \mathrm{Effects} \mathrm{of}$ Biochar Amendment on Soil Physical and Chemical Properties: Current Status and Knowledge Gaps .J. Advances in Earth Science, 29(1): 68-79.

31. Yuan J H, Xu R K, Zhang H. (2011) The forms of alkalis in the biochar pro- duced from crop residues at different temperatures.J. Bioresource tech- nology, 102( 3) : 3488-3497. 
32. Liu Y X, Lu H H, Yang S M, et al. (2016) Impacts of biochar addition on rice yield and soil properties in a cold waterlogged paddy for two crop seasos .J. Field crops research, 191: 161-167.

33. Xu R K, Yuan J H. (2011) The amelioration effects of low temperature biochar generated from nine crop residues on an acidic Ultisol.J. Soil use and management27( 1) : $110-115$.

34. Li M, Li Z P, Liu M, et al. (2015) Effects of Different Straw Biochar on Nutrient and Microbial Community Structure of a Red Paddy Soil .J. Scientia Agricultural Sinica, 48(7):13611369.

35. Qiu Z . ( 2019 ) Effects of Spartina alterniflora-derived biochar on Remediation of Cadmium Contaminated Soil and its mechanisms [D]. Shanghai: East China Normal University.

36. Shi Y L, Gao P L, Liu X R, et al. (2019) Increased microbial biomass in coastal saline fields of North China Plain by application of biochar and organic manure .J. Journal of Plant Nutrition and Fertilizers, 25(4) : $555-567$.

37. Singh B P, Hatton B J, Singh B, et al. (2010) Influence of biochars on ni- trous oxide emission and nitrogen leaching from two contrasting soils.J . Journal of environmental quality , 39( 4):1224-1235.

38. Guo C L, Li N, Peng J, et al. (2018) Direct returning of maize straw or as biochar to the field triggers change in acidity and exchangeable capacity in soil .J. Journal of Plant Nutrition and Fertilizers, 24 ( 5) : $1205-1213$.

39. Han X R, Jiang H Y, Guo C L, et al. (2016) Effects of New Chelate Fertilizer on Yield,Nutrient Uptake and Nutrient Use Efficiency of Maize .J. Journal of Shenyang Aricultural University, 47( 2) : 159 165.

40. Zhang Z R. (2014) A Preliminary Study on the Effect of Biochar on Soil Physical Properties [D]. Hangzhou: Zhejiang University.

41. Sarfraz R, Shakoor A, Abdullah M, et al. (2017) Impact of integrated application of biochar and nitrogen fertilizers on maize growth and nitrogen recovery in alkaline calcareous soil.J. Soil science and plant nutrition, 63 (5):488-498.

42. Kang R F,Zhang R M, Shi J, et al. (2014) Effects of biochar-based fertilizer on soil fertility, wheat growth and nutrient absorption .J. Soil and Fertilizer Sciences in China, 2014(6):33 -38.

43. Liu F, Feng S J, Zhang L Y, et al. (2014) Influence of Applying Biochar on Soil Available Nutrients and Soil Moisture at Continuous Vegetation Plantations of Karst Hilly Areas .J . Northern Horticulture, 2014( 7) : 158-162.
44. Wei Y X, Shi G X, Feng C, et al. (2019) Effects of Applying Biochar on Soil Structure and Soybean Yield on Slope Farmland in Black Soil Region .J. Transactions of the Chinese Society for Agricultural Machinery, 50(8):309-320.

45. Efthymiou A, Gronlund M, Muller-Stover D S, et al. (2018) Augmentation of the phosphorus fertilizer value of biochar by inoculation of wheat with selected Penicillium strains.J. Soil biology and biochemistry, 2018( 116) : $139-147$.

46. Song D L, Xi X Y, Huang S M, et al. (2017) Effects of combined application of straw biochar and nitrogen on soil carbon and nitrogen contents and crop yields in a fluvo-aquic soil .J. Journal of Plant Nutrition and Fertilizers, 23(2):369-379.

47. Shang J, Geng Z C, Chen X X, et al. (2015) Effects of Biochar on Soil Organic Carbon and Nitrogen and Their Fractions in a Rainfed Farmland .J. Journal of Agro-Environment Science, 34 ( 3 ) : $509-517$.

48. Feng L, Zhou J, Dong Y B, et al. (2019) Effects of biochar on mitigating nitrous oxide emission from an intensive vegetable field and crop yields .J. Journal of Plant Nutrition and Fertilizers, 25( 7) :1115 - 1124.

49. Li L, Wang X Y, Tian Y F, et al. (2018) Effects of biochar on soil nutrients, yield and quality of vegetables .J. Journal of Plant Nutrition and Fertilizers, 24 ( 5) : $1237-1244$.

50. Lv Z X. (2017) Effects of Biochar and Biochar Compound Fertilizer Application on Crop Yield and Economic Benefits [D] . Nanjing :Nanjing Agricultural University.

51. Dong X L. ( 2017 ) The effect of long-term application of biomass charcoal on carbon pool and crop yield [D] . Beijing: China Agricultural University.

52. Kuang C T, Jiang C Y, Li Z P, et al. (2012) Effects of biochar amendments on soil organic carbon mineralization andmicrobial biomass in red paddysoils .J. Soils, 44(4) : $570-575$.

53. Bargmann I, Martens R, Rillig M C, et al. (2013) Hydrochar amendment promotes microbial immobilization of mineral nitrogen.J. Journal of Plant Nutrition and Soil Science, 177(1):59-67.

54. Tao P C, Chen X M, Jin Z W, et al. (2016) Effects of Biochar Combined with Nitrogen Fertilizers on Microbial Biomass C,N and Carbon-to-nitrogen Ratio of Upland Red Soil .J. Journal of Soil and Water Conservation, $30(1): 231-235$.

55. Fang Y Y, Singh B P, Luo Y, et al. (2018) Biochar carbon dynamics in physically separated fractions and microbial use efficiency in contrasting soils under temperate pastures.J. Soil biology and 
biochemistry, 2018( 116) : $399-409$.

56. Li R X, Li H J, Huo Y L, et al. Effect of biochar on root morphology and endophytic fungal diversity of winter wheat in North China[J /OL]. Transactions of the Chinese Society for Agricultural Machinery, 2018, 49(3) : $235-242$.

57. Zavalloni C, Alberti G, Biasiol S, et al. (2011) Microbial mineralization of biochar and wheat straw mixture in soil: a short-term study.J. Applied Soil Ecology, 50: $45-51$.

58. Dempster D N, Gleeson D B, Solaiman Z M, et al. (2011) Decreased soil microbial biomass and nitrogen mineralisation with Eucalyptus biochar addition to a coarse textured soil.J. Plant and Soil, 354(1):311-324. 